\title{
Juan Radrigán, veinticinco años de teatro, 1979 - 2004 \\ (Un comentario general a propósito de marginalidad y memoria, dictadura, transición y postdictadura en Chile)*
}

\section{Adolfo Albornoz Farías}

Universidad del Bío-Bío

adoalbornoz@udec.cl

\section{RESUMEN}

Juan Radrigán ha cumplido, durante la temporada teatral 2004, veinticinco años como dramaturgo, período durante el cual ha llegado a ser uno de los más importantes autores en la historia del teatro chileno. Este artículo ofrece una mirada panorámica sobre estos veinticinco años de producción dramatúrgica y teatral de Juan Radrigán, desde sus obras más emblemáticas estrenadas al final de los años setenta e inicio de los ochenta, en las que aborda fundamentalmente la marginalidad en el contexto del autoritarismo, algunas de las cuales ya forman parte de los clásicos del teatro chileno, hasta las piezas más recientes y menos conocidas del autor, en las que se refiere principalmente a la memoria en el contexto de la democracia, y con las que Juan Radrigán activamente se ha proyectado como dramaturgo para el siglo XXI.

Palabras claves: Teatro, teatro chileno, historia del teatro chileno, escritura teatral, dramaturgia, literatura dramática, artes escénicas.

* Este artículo ofrece una reelaboración y ampliación del Prólogo "Juan Radrigán, veinticinco afanosos años entretextos y escenas", que introduce la antología de Juan Radrigán, Crónicas del amor furioso. Santiago, Chile: Ediciones Frontera Sur, 2004, 400 páginas; volumen que obtuvo el Premio a la M ejor 0 bra Literaria Género Teatro 2005, reconocimiento que entrega anualmente el Consejo $\mathrm{N}$ acional dela Cultura y las Artes a través del Consejo $\mathrm{N}$ acional del Libro y la Lectura. Dicha antología reúneun texto testimonial de Juan Radrigán, M emorias del olvido, 2002; y doce de sus obras de teatro -la mayoría de su producción más reciente-: El desaparecido, 2004; Beckett y Godot, 2004; D igo siempre adiós, y me quedo, 2002; Esperpentos rabiosamenteinmortales, 2002; El exilio dela mujer desuda, 2001; M edea mapuche, 2000; Perra celestial, 1999; El príncipedesolado, 1998; Fantasmasborrachos, 1997; El encuentramiento, 1995; Pueblo del mal amor; 1986 y Borrachos de luna, 1986. 


\section{ABST RACT}

Juan Radrigán has celebrated during the 2004 Theatrical Season twenty five years as a playwright. D uring this period he became one of the most important authors on Chilean Theatre history. This article offers a panoramic view about this twenty five years of Juan Radrigán's dramatic and theatrical production, from hismost emblematic plays premiered at the late 70 's and early 80 's, in which he fundamentally highlights exclusion in the context of authoritarianism - some of those works are already part of $C$ hilean Theatre Classics-, until the author's newest and least known plays, in which he mainly refers to memory in the context of democracy -works that have actively proyected Juan Radrigán as a playwright for the XXI century.

Keywords: Theatre, chilean theatre, chilean theatre history, playwriting, dramaturgy, dramatic literature, performing arts.

Recibido: 10-09-2005. Aceptado: 21-11-2005

\section{INTRODUCCION}

| UAN Radrigán ha cumplido, durante la temporada teatral 2004, veinticinco afanosos años desde que apareciera como dramaturgo sobre los escenarios de Chiley el mundo, período duranteel cual sin duda seha posicionado como uno de los más importantes autores en la historia del teatro chileno. La ocasión lo ha encontrado, además, en plena vigencia y productividad. A modo de ejemplo: mientras un nuevo proyecto editorial, Ediciones Frontera Sur, ha inaugurado su catálogo publicando, casi al finalizar el año 2004, la antología Crónicas del amor furioso, que reúne prácticamentetoda la obra más reciente y menos conocida de Juan Radrigán, al iniciarse el año 2005 la comunidad artística chilena ha pre miado el trabajo del autor otorgándole el Premio Altazor en la categoría M ejor D ramaturgia 2004 por su obra Beckett y $G$ odot, llevada a escena por el Teatro de la Universidad Católica durante el primer semestre de dicha temporada; por su parte, Juan Radrigán claramente ha sorprendido al público, a la prensa, a la críticay en particular a sus pares al estrenar, duranteel segundo semestredel año 2004, junto a dos actores peruanos, en la Plaza de Armas de Santiago, la obra Carta abierta, haciéndose cargo ahí de una delas más sensibles problemáticas de la contingencia nacional, la migración peruana en Chile, reafirmando con ello la que ha sido una de las características fundamentales de toda su creación teatral: su envidiable saber estar tan lúcidamente en el presente (C astro, 2005).

La producción dramatúrgica deJuan Radrigán, que ya suma más de treinta títulos, puede ser estructurada y comprendida en base a dos grandes períodos y un intermedio. El primero de éstos se inicia con el estreno, en 1979, de su obra inaugural, Testimonio de las muertes de Sabina, dirigida por Gustavo M eza para 
el Teatro de Comediantes, y abarca todas las piezas escritas y llevadas a escena por el autor en el contexto dela dictadura militar chilena. Las obras más emblemáticas de este período, como Las brutas (1980), H echosconsumados(1981) y EI loco y la triste (1982), entre otras, han sido amplia y sistemáticamente difundidas - publicadas, estrenadas y estudiadas- durante más de dos décadas en Chile y el extranjero.

Con el final del gobierno militar y el inicio del proceso de transición a la democracia sobreviene un relativo, pero significativo silencio de algunos años en la producción de Juan Radrigán.

El segundo período en el devenir dramatúrgico del autor se inicia con el estreno, en 1995, de El encuentramiento, dirigida por W illy Semler para la Primera $M$ uestra de $D$ ramaturgia $N$ acional, y reúne la producción escrita y estrenada en el marco de la postdictadura. De las obras correspondientes a este período, como Fantasmas borrachos (1997), El príncipe desolado (1998) y Perra celestial (1999), entre otras, hasta antes de la antología C rónicas del amor furioso (2004), al gunas habían aparecido en revistas especial izadas y/o en ediciones de reducida circulación, pero en términos generales casi todas no eran y aún no han sido conocidas mucho más allá que por los espectadores que asistieron a la primera y única versión escénica profesional con que la mayoría de estos títulos ha contado dentro deC hiley/o por algunos pocos especial istas que han comentado al gunas de estas piezas.

Este artículo busca perspectivizar desde una mirada panorámica eintegradora diversos aspectos de este primer cuarto de siglo de actividad dramatúrgica y teatral de Juan Radrigán, desde sus obras más emblemáticas estrenadas al final delos años setenta e inicio de los ochenta, en las que aborda fundamentalmente la marginalidad en el contexto del autoritarismo, algunas de las cuales ya forman parte de los clásicos del teatro chileno, hasta las piezas más recientes y todavía menos conocidas del autor, en las que se refiere principalmente a la memoria frente al desafío de la reconstrucción democrática, y con las que Juan Radrigán activa y enérgicamente se ha proyectado como hombre de teatro y como productor cultural para el siglo XXI.

\section{PRIMER PERIO DO, TEAT RO -M ARGIN ALID AD - Y DICTADURA, 1979-1990}

El primer período en la producción dramatúrgica de Juan Radrigán, desde su aparición con Testimonio de las muertes de Sabina, en 1979, hasta el estreno de Piedra de escándalo, en 1990, puede ser caracterizado en base a tres aspectos fundamentales: a) el contexto político y cultural que determina la llegada del 
autor a la escena teatral chilena, b) la activa y permanente vinculación que establece con el medio teatral nacional e internacional, y c) la particular reflexión que realiza desde el teatro sobre la marginalidad social en condiciones de autoritarismo.

Juan Radrigán forma parte de aquella primera generación de creadores nacionales que frente al golpe de estado del 11 de septiembre de 1973 y la consiguiente dictadura logran, tras al gunos años derelativo apagón cultural, articular un heterogéneo coro de voces disidentes, resistentes o contestatarias al gobierno militar. En el teatro, Juan Radrigán comparte este escenario postgol pe con otros dramaturgos que también contribuyen a renovar los registros de la escritura teatral chilena, como D avid Benavente (Pedro, Juan y D iego, 1976), LuisRivano (Tellamabas Rosicler, 1976) y M arco Antonio de la Parra (M atatangos, 1978), entre otros; y con directores, actores y diseñadores que luego de la clausura por parte del autoritarismo del proyecto de desarrollo cultural impulsado hasta ese momento por los teatros universitarios, de los que son herederos, logran reinventarse fuera del circuito institucional a través de nuevas compañías independientes, como Teatro La Feria de Jaime Vadell (H ojas de Parra, 1977), Teatro Imagen de G ustavo M eza (El último tren, 1978) y Taller delnvestigación Teatral de Raúl O sorio (Tres M arías y una Rosa, 1979), entre otras.

Todosellos, deuna u otra forma, en el texto y en la escena, tienden a tematizar el colapso de los proyectos históricos individuales y colectivos, la perplejidad o frustración consecuentes y la evidente incertidumbre, relativa esperanza o definitiva desesperanza frente al futuro. Todos ellos, además, tienden a asumir el hecho teatral como una urgencia, revalorizando su potencial dialógico rápido y directo para con el espectador y la comunidad, especialmente en condiciones de represión. En palabras de Juan R adrigán: "Escribo teatro, además de una razón de oficio, porque considero que es la manera más directa de entablar diálogo con la gente. El teatro es una conversación de hombrea hombre para romper el silencio" (1994: 96).

Por lo anterior, y a pesar de que el autor incursiona en diversos géneros literarios antes de llegar al teatro -en 1962 publica el volumen de cuentos L os vencidos no creen en Dios, en 1968 la novela El vino de la cobardía y en 1975 el poemario El día de los muros, entre otros títulos-, al arribar a la dramaturgia, a los cuarenta y dos años de edad, Juan R adrigán - a diferencia de otros numerosos dramaturgos nacionales que entienden el oficio desde una perspectiva más cercana a la idea tradicional de "escritor"- renuncia al trabajo puramenteliterario en favor de la escritura teatral, es decir, reconoce y asume la experiencia escénica como condición y sentido esencial para su escritura, gracias a lo cual se vincula indisolublemente a mucho de lo más atractivo y significativo del panorama escénico chileno de su tiempo. 
Una rápida mirada al quehacer del autor durante la década del ochenta (Zegers, 1999) permite constatar, por ejemplo, que luego de que la primera obra de Juan Radrigán, Testimonio de las muertes de Sabina, es llevada a escena, en Santiago, por el Teatro de Comediantes bajo la dirección de G ustavo M eza, al año siguiente, 1980, el dramaturgo coescribe Viva Somoza con el mismo director, quien estrena el nuevo título junto al Teatro Imagen. En forma paralela comienza a desplegarse la presencia verdaderamente nacional de Juan Radrigán cuando su tercera obra, Las brutas, es estrenada en Valparaíso por la Compañía El Farol y en Concepción por el Teatro El Rostro. Durante la temporada siguiente, 1981, el autor aparecejunto a su propio grupo, el recién formado Teatro Popular El Telón, con el quelleva a escena muchas de sus siguientes obras y en muy diversas condiciones: desde espacios marginales de la ciudad, pasando por sal as teatrales céntricas independientes o comerciales, hasta festivales en el extranjero; a la vez, el autor comienza a recibir los primeros reconocimientos formales como dramaturgo. Radrigán y El Telón estrenan en 1981 H echos consumados, reconocida como M ejor O bra Chilena del Año, y en $1982 \mathrm{El}$ toro por lasastas, que recibeel Premio del Círculo de Críticos de Arte y el Premio M unicipal de Literatura de Santiago; paralelamente aparece en Chile la primera publicación que recoge el teatro de Juan Radrigán, H echos consumados. Tres obras (1982). Al año siguiente, 1983, el todavía novel dramaturgo ya polemiza con el medio teatral chileno a través de su Epístola a los teatristas desorientados e inmediatamentedespués, con sus dosúltimosestrenos, el primero dirigido por N elson Brodt (H echos consumados) y el segundo por Alejandro Castillo (El toro por las astas), Juan Radrigán y el Teatro Popular EI Telón emprenden su primera aventura internacional: asisten al Festival de Teatro de $\mathrm{N}$ ancy, Francia, tras lo cual real izan una exitosa gira por cerca de diez países europeos, mientras quedurante la temporada siguiente, 1984, con El loco y la triste, dirigida por Raúl 0 sorio, en el Festival deTeatro de M anizales, Colombia, se consolida la presencia del autor en el extranjero. Paral elamente aparece la primera publicación de registro internacional que contiene la obra del dramaturgo, Teatro de Juan Radrigán: 11 obras (1984) y también durante ese mismo año, 1984, H echos consumadoses llevada al cine por el director Luis Vera. Así, estrenos, premios, publicaciones, giras y reconocimientossesuceden ininterrumpidamentehastael final delosañosochenta, convirtiéndose J uan Radrigán, con al rededor de veinte obras estrenadas durante ese período, en el dramaturgo chileno más destacado de la década.

En general, las obras de este primer período de la producción dramatúrgica de Juan Radrigán mayoritariamente han sido lédas por la crítica como una proposición de teatro social y político, y más específicamente, como un discurso centrado en la figura del marginal y a la vez contestatario a la dictadura militar. D esde esta perspectiva, el autor establece continuidad con uno de los 
principales tópicos de la producción teatral y literaria chilena y latinoamericana del siglo XX, la marginalidad, pero reelaborando su abordaje en el contexto del autoritarismo (H urtado y Piña, 1984). Así, su dramaturgia se entiende también como un intento de diálogo y discusión pública sobre problemáticas políticas y económicas, sociales y culturales, en un momento en que dicha posibilidad dialógica aparece ciertamente restringida a través de la mayoría de los canales regularmente establecidos para ello (V idal, 1984). En esta apuesta, la utopía o posibilidad de una eventual reconstrucción humanizadora emerge como gesto expresivo fundamental en la poética del autor (Cánovas, 1986).

A hora bien, los seres humanos socialmente marginados que en forma casi exclusiva pueblan y protagonizan el teatro de Juan Radrigán - cesantes, alcohólicos, vagos, prostitutas, enfermos, desalojados, infractores de la ley, trabajadores precarios, etc.- no se caracterizan sólo por su amplia y general exclusión del sistema social, es decir, de bienes, servicios y derechos básicos, sino más específicamente por su condición de ex integrados (o neo marginados), repentina y violentamente excluidos tras la instalación de un nuevo y opresivo orden y poder político y económico. Tras la catástrofe, la marginalidad no es sólo material sino también simbólica; luego de haber sido apartadoso expulsados del mundo, aquél los ya casi muertos en vida están cercanosa quedar al margen incluso desu propia humanidad.

Juan Radrigán asume en su dramaturgia el compromiso con la representación del mundo, la perspectiva y el discurso de aquellos con menos posibilidades de al canzar a ser considerados - vistos y/o escuchados- en el entramado social cotidiano. En este intento sus personajes emergen como portadores de una significativa densidad histórica y cultural, propia del mundo popular y del registro oral, recuperada en su autonomía, validez y dignidad. A la vez, este rescate no es idealizador ni complaciente, no hay en el autor conmiseración para con sus personajes sino el máximo de exigencia, obligándolos a enfrentarse con la mayor dureza a sí mismos como condición esencial para acceder a una eventual rehumanización. Por último, y en tanto lo anterior ocurre siempre en situaciones límite, la intensidad de esta experiencia existencial contribuye finalmente a superar la estrecha caracterización socioeconómica de los personajes de la ficción para abrir la interpretación de la misma hacia una reflexión sobre la condición humana en general.

\section{INT ERMED IO, TEAT RO -SILEN CIO - Y TRAN SICIO N, 1990-1994}

El final de la dictadura militar chilena y la llegada de la democracia o más bien el inicio del proceso de redemocratización, a partir de 1990, impactan en Juan 
Radrigán, así como en muchos de los creadores nacionales más activos durante los años setenta y ochenta, hasta el autismo o mutismo. En el caso específico del autor teatral, los casi cinco años de silencio dramatúrgico experimentados por Juan Radrigán durante la primera mitad de la década del noventa son apenas interrumpidos básicamente por un solo hecho significativo, la obral slas de porfiado amor es incluida en la segunda edición de Teatro de Juan Radrigán: 11 obras, de 1993, y paral elamente es llevada a escena por el Teatro Popular El Telón.

Si la producción teatral de Juan Radrigán de los años ochenta ilustra sobre al gunas de las formas posibles deresistir y contestar al poder autoritario desde la escritura y el escenario, el sintomático silencio del dramaturgo durante el inicio de los años noventa evidencia la dificultad para mantener o adecuar un discurso crítico desde una trinchera más cercana al oficialismo. ¿Cómo continúa desarrollando su oficio un autor teatral cuya entera biografía como dramaturgo y hombre de teatro radica en la oposición a la dictadura una vez que ésta ha terminado? ¿D esde dónde o de qué hablar frente a las nuevas condiciones que vive el país? ¿Escribir por escribir? ¿Representar por representar? ¿O abandonar el oficio teatral?

En medio del particular tránsito chileno hacia la democracia y una vez que ha comenzado a evidenciarse con claridad una postdictadura basada en la búsqueda de supuestos y a veces apresurados consensos que faciliten una eventual reconciliación, Juan Radrigán se detieney reflexiona sobre el estado de las cosas en el país y a la vez entrega luces sobre lo que posiblemente será el futuro de su escritura:

El daño hecho por un puñado de insensatos que jugaron a ser dioses es siempre superior a cien años, puesto que se pueden volver a levantar los puentes, se pueden volver a echar a andar las fábricas y es posible recuperar las riquezas nacionales vendidas, pero no se puede curar de la noche a la mañana el daño inmenso hecho a las personas. No viviré el tiempo suficiente para ver al país sin heridas. Pero en todo caso, si no escribí comedias ni café concert bajo la dictadura, no veo por qué podré hacerlo hoy o mañana (1994: 98).

\section{SEG UN D O PERIO DO, TEATRO -MEM ORIA-Y POST DICTAD URA, 1995-2004...}

El segundo período en la producción dramatúrgica de Juan Radrigán, desde su reaparición con El encuentrami ento, en 1995, hasta el estreno de B eckett y $G$ odot y Carta abierta y la publicación en la antología Crónicas del amor furioso de un nuevo texto aún sin estrenar, El desaparecido, todo esto en el año 2004, puede ser caracterizado - siguiendo el esquema propuesto para el comentario sobre el 
primer período- en base a tres aspectos fundamentales: a) el nuevo contexto político y cultural en el que el teatro del autor se reinserta en la vida pública chilena, b) la revinculación que establece con el medio artístico y teatral nacional y la comunidad internacional, y c) la particular reflexión que realiza desdeel teatro sobre la memoria individual y colectiva frente al desafío de la reconstrucción y normalización de la convivencia democrática en el país.

Juan Radrigán participa de la escena pública chilena de los años noventa como parte de aquella generación de creadores nacionales que, luego de oponerse contestataria o refractariamente a la dictadura militar, reelabora y continúa su producción asumiendo posiciones más próximas o de mayor distancia crítica para con el proceso de redemocratización política, económica, social y cultural conducido en Chile a partir del 11 de marzo de 1990 por los gobiernos de la Concertación. En el teatro, Juan Radrigán comparte este escenario postdictatorial con otros dramaturgos que a través de varias décadas igualmente han transitado en y con su obra por distintos momentos del devenir nacional, como Jorge D íaz (La paloma y el espino, 1957; El velero en la botella, 1962; Toda esta larga noche, 1976; D icen quela distancia esel olvido, 1985; L a cicatriz, 1996; Fanfarria para marionetas, 2001), M arco Antonio de la Parra (L o crudo, lo cocido, lo podrido, 1978; La secreta obscenidad decada día, 1984; La pequeña historia de Chile, 1994; Estamos en el aire, 2001) y Ramón Griffero (Cinema-U toppia, 1985; Río abajo, 1995; Tus deseos en fragmentos, 2003), entre otros; y con directores, actores y diseñadores que luego de superado el esquema oficialismo/oposición en el que nacieron a la vida artística, logran reformular la labor de sus compañías a la luz de la nueva situación del país, como Gran Circo Teatro de Andrés Pérez (La negra Ester, 1988; El desquite, 1995; La H uida, 2001), Teatro Fin de Siglo de Ramón Griffero (Cinema-U toppia, 1985/2000; Extasis, 1993/ 2004; Tus deseos en fragmentos, 2003) y Teatro La M emoria de Alfredo Castro (La manzana de Adán, 1990; M ano de obra, 2003), entre otros.

Todosellos, de una u otra forma, en el texto y en la escena, tienden a tematizar un espíritu de época confuso en el que diversos marcos referenciales como transición, redemocratización, postdictadura, postmodernidad, fin de siglo, neoliberalismo y globalización, entre otros, tensionan y fragmentan eventuales proyectos individuales a la vez que dificultan su posibilidad de fundirse con iniciativas colectivas en una síntesis trascendentey/o humanizadora. Todos ellos, además, tienden a situar su teatro, más que en el ámbito tradicional del "arte", en el campo de la producción cultural, desdibujándose desde ahí las habituales fronteras entre estética y política en favor de un continuo significante en el que desde la cultura se apuesta respecto de cómo se construye sociedad, por ejemplo, en el caso específico del Chile actual, enfrentando el cómo hacerse cargo del pasado y su memoria (o su olvido). En palabras de Juan Radrigán: 
N unca sabremos de dónde nos viene de pronto esa necesidad imperiosa de ponernos a juntar palabras que cuenten historias que testimonien, protesten 0 reflexionen sobre el tiempo en que nos tocó existir; éste es quizás el único misterio bueno de la vida (...) Sin embargo, si tuviese que graficar hoy toda la tragedia demi país en una imagen... escogería la faz de alguno de los cientos de torturad os por la dictadura militar que nos asoló... y que nos sigue destruyendo, ahora desde la sombra. Es decir, escogería el rostro de una madre loca que mece a su hijo muerto hace mucho tiempo. Escogería esta imagen y no la de un pobre, porque afrentosa y execrable, la pobreza posee una cierta racionalidad, es al go que podemos comprender 0 al menos tratar de hacerlo. Pero en el odio abismal... no existe asomo al guno de racionalidad (2004a: 17-18).

Si el teatro de Juan Radrigán de la década del ochenta representa, frente a la dictadura, un intento de discursividad política, es decir, de discusión pública sobre problemáticas de interés colectivo, la producción dramatúrgica del autor desde los años noventa y hasta hoy no hace más que insistir en la misma intencionalidad señalando críticamente, en el marco de la postdictadura, la posibilidad de una real idad distinta frenteal estado de las cosas, en especial a propósito de cómo el país ha enfrentado las heridas originadas en su pasado más reciente: "Somos un pueblo que no se dio tiempo para llorar a sus muertos, que no incorporó a sus entrañas la brutal derrota sufrida", ha insistido el autor (cit. por Zegers, 1999: 193).

El nuevo contexto democrático, sin embargo, no ha condenado una dramaturgia de fuerte discurso crítico como la de Juan Radrigán a transitar por canales de exhibición y/o difusión mayoritariamente marginales, como ocurrió durante la década del ochenta, período en el cual, según el autor, el Teatro Popular el Telón "fue el grupo teatral al que más multas se le aplicó" por parte de la dictadura (1994: 98). Al contrario, el panorama cultural postdictatorial ha permitido y facilitado la permanente vinculación del dramaturgo con mucho de lo más institucional y oficial del arte nacional así como con algunos de los principales referentes en materia de experimentación y renovación de la escena chilena de la última década, transitando activamente el autor por las variadas dualidades de registros culturales, como institucional/independiente u oficial/ autónomo, y por los múltiples pliegues en los que éstos, a veces confusa y/o contradictoriamente, tienden a fusionarse en la vida nacional actual, cuyos órdenes son permanentemente reformulados según las necesidades del mercado.

Por ejemplo, luego de que la primera obra de este segundo período en el teatro de Juan Radrigán, El encuentramiento, es seleccionada, en 1995, para la Primera M uestra de D ramaturgia N acional, la iniciativa gubernamental más emblemática en materia de políticas cultural es relativas al teatro durante el proceso de redemocratización, el autor resulta seleccionado tres veces más en dicho 
certamen - con Fantasmas borrachos en 1997, El príncipe desolado en 1998 y Esperpentos rabi osamente inmortales en 2002-, a la vez que participa como jurado en otras versiones del mismo evento. La segunda obra de este período, Fantasmas borrachos, luego de ser mostrada en la mencionada M uestra $\mathrm{N}$ acional de 1997, es reestrenada ese mismo año por el Teatro $\mathrm{N}$ acional Chileno (Teatro de la Universidad de Chile), Ilegando así la dramaturgia de Juan Radrigán por primera vez al más emblemático escenario teatral del país durante el siglo XX, completamentevedado por la dictadura militar durante los años setenta y ochenta para los dramaturgos nacional es surgidos durante ese período. Con este estreno, además, se produce el trascendente y productivo encuentro sobre el escenario entre Juan Radrigán y Rodrigo Pérez, el más importante director chileno surgido durante los años noventa en materia de autoría escénica, quien dirige cinco de la decena de obras estrenadas por Juan Radrigán durante la última década -Fantasmas borrachos en 1997, El prínci pe desolado en 1998, Perra cel estial en 1999, M edea mapucheen 2000 y D igo siempre adiós, y mequedo en 2002-, además de al gunas interesantes nuevas versiones de obras del período anterior, entre ellas Pueblo del mal amor y Las brutas, esta última llevada a escena por el director chileno en el Centro D ramático $\mathrm{N}$ acional de $\mathrm{N}$ ormandía, Francia. También en el Teatro $\mathrm{N}$ acional Chileno, y aunque sólo se produce una vez, es significativo el encuentro entre el autor y Alfredo C astro, otro de los más importantes directores chilenos de los últimos veinte años, quien en 1999 reestrena H echos consumados en ese importante escenario, versión que también se presenta con éxito en el extranjero y que contribuye decididamente a instalar esta obra de Juan Radrigán -junto a Las brutas- entre los clásicos del teatro chileno; a propósito del efecto que estas direcciones/autorías escénicas han producido sobre su propia escritura, Juan Radrigán ha reconocido: "Es como si las obras tuviesen hoy un significado más profundo que antes" (cit. por Guerrero, 2001: 147). Con Fantasmas borrachos, además, comienzan a llegar nuevamente los premios y reconocimientos formales para el dramaturgo, recibe el Premio de la Asociación de Periodistas de Espectáculos a la M ejor O bra del Año 1997 y luego, en 1998, el Premio J osé N uez M artín, del Instituto de Letras de la Pontificia U niversidad C atólica de C hile. D e esta misma institución, el Teatro de la U niversidad Católica, Juan Radrigán recibe la invitación para escribir por encargo dos de sus últimos trabajos, D igo siempreadiós, y me quedo y Beckett y Godot, estrenados en los años 2002 y 2004, respectivamente, recibiendo por el último el Premio Altazor 2005. Por cierto, el autor también continúa vinculado en forma permanente a la actividad teatral en regiones; en Concepción, por ejemplo, encabeza desde el año 2001 el jurado del Concurso-M uestra D ramaturgia del Sur, de la Escuela deArte D ramático del Sur, mientras quea la vez, cuando en el año 2003 la U niversidad de Concepción, después de treinta años, intenta resu- 
citar su proyecto de teatro profesional clausurado tras el golpe de estado, lo hace produciendo Fantasmas borrachos, dirigida por Francisco Albornoz. Paralelamente, Juan Radrigán comienza a desarrollar intensamente la actividad docente, primero a través de su propio Taller de D ramaturgia -el que en al gunos de sus proyectos es apoyado por otra importante iniciativa cultural gubernamental como el Fondo de D esarrollo de las Artes y la Cultura, que también respalda otras iniciativas vinculadas a la obra del autor- y después a través de su incorporación formal como académico a escuelas de teatro como las de la Universi dad de Chile y U niversidad Arcis. Finalmente, la comunidad teatral internacional, junto con interesarse por contar con la presencia de Juan Radrigán y/o al gunos montajes desus piezas en diversos encuentrosy eventos en el extranjero, evidencia también un creciente interés por traducir, estrenar y publicar su obra en el exterior.

En general, las obras de este segundo período dela producción dramatúrgica de Juan Radrigán aún no han sido detenida y atentamente conocidas, leídas y comentadas por la crítica. Entendiendo su escritura como "una sola gran obra", la dramaturgia de Juan Radrigán, incluyendo sustítulos más recientes, ha tendido a seguir siendo mayoritariamente tematizada, tanto dentro de C hile (Zegers, 1999) como fuera del país (Bravo, 2000), en función de las premisas fundamentales con las que se la leyó en la década del ochenta, es decir, como una proposición de teatro social y político, centrado en abordar variadas facetas propias de la condición marginal para ponerlas en relación con diversos ámbitos propios de la experiencia autoritaria. Dicha interpretación sin duda continúa siendo pertinente, sin embargo, los cambios de contexto y los nuevos marcos referenciales también son lo suficientemente significativos como para necesitar ser incorporados y precisados.

Efectivamente el teatro de Juan Radrigán sigue siendo político al entablar un diálogo franco con el estado de las cosas y/o el espíritu de la época, es decir, en el caso de su producción más reciente, con el Chile de la transición y de la posdictadura. En este escenario el autor encarna y defien de en y con su escritura y a través de sus personajes y escenas, fundamentalmente la facultad para no consentir y para no dejarse gobernar. En un marco de banalidad y desprestigio generalizado del discurso y el debate públicos, especialmente a través de sus canales más regulares, Juan Radrigán insiste en la posibilidad de la escritura y la representación como experiencias portadoras de contenido. El autor no accede al gesto posmoderno de citas y reciclajes, juegos formales y permanentes reacomodos, dentro del cual más que a una voluntad de transformación de la realidad se asiste al permanente reposicionamiento dentro de las condiciones dadas. Por el contrario, los personajes de las obras de Juan Radrigán sí son portadores de un eventual proyecto histórico y transformador, que es subjetivo y 
existencial, y que en primer término remite al compromiso individual como forma límite de acción, dentro de la cual la reivindicación de la memoria y el ajuste de cuentas adquieren una dimensión esencial. Así, devienen una escritura teatral y un habla escénica intransigentes, insobornables, tajantes y por lo mismo agobiantes, y es éste el gesto que sin duda resulta marginal en el Chile actual, es decir, en el Chile de los consensos. En palabras del autor:

La vida dice que a pesar de los hombres arrojados al mar, que a pesar de los sepultados en cal dentro de los hornos y de los hijos de las violaciones, aún se puede ser feliz. Y yo digo que no, que esa felicidad es una afrenta para los torturad os y asesinados, que sin castigo para los culpables, sin justicia, no habrá civilización posible. Y siguiendo este diálogo siniestro, la vida pone como prueba viviente de su teoría a cientos de exiliados, torturados y familiares de desaparecidos que han vuelto a formar un hogar y han vuelto a creer en algo. Y yo digo que no, que la impunidad terminará por convertirnos en animales apaleados a los que los golpes ya no duelen ni humillan (2004a: 18-19).

\section{FIN AL}

La dramaturgia de Juan R adrigán se inscribe en primer lugar en los registros del teatro y a partir de ahí se instala con propiedad también en los de la literatura. D e hecho, del conjunto de dramaturgos surgidos en Chileen el mismo período y contexto - final de los años setenta einicio de los ochenta, en plena dictaduraes uno de los autores teatrales cuya escritura dramática más activa, variada y permanentemente se ha mantenido en diálogo y relación con el devenir del arte escénico chileno durante las últimas tres décadas, transitando las obras de Juan Radrigán por los circuitos marginal, oficial y comercial, por la producción independiente einstitucional, por escenarios regionales y capitalinos, por el registro popular, tradicional y experimental, y por el campo aficionado y profesional, entre otros, así como por los múltiples pliegues en los que todos ellos muchas veces pueden entrecruzarse. Buena parte de los actores, directores y diseñadores que han dado vida al teatro chileno durante los últimos veinticinco años han participado por lo menos alguna vez en la producción de una obra de Juan Radrigán, a la vez que todos los estudiantes de teatro formados en el país durante los últimos quince años han lédo y estudiado al autor y además muchos de ellos han ejercitado las bases del oficio teatral con alguna obra o escena de él. Parala mayoría dela opinión pública chilena el nombre de Juan Radrigán resulta relativamente familiar y dentro de ésta buena parte del público de teatro ha visto alguna vez una obra del autor. 
Lo anterior ha sido posible gracias a la fuerza de una escritura dramática que, manteniendo siempresu conexión esencial con la experiencia escénica y su compromiso vital con los menos favorecidos, ha sabido conservar, profundizar y complejizar a través de un cuarto de siglo su permanente pertinencia frente al estado de las cosas en Chile a la vez que ha logrado evidenciar una creciente universalidad; cada vez más la obra de Juan Radrigán "lee" al espectador/lector mucho más que éste a la obra. Así, la dramaturgia del autor se ha convertido en claro testimonio de una singular forma de enfrentar y comprender en primer término la particular historia nacional, pero también la condición humana en general.

La reflexión que sobre la marginalidad y la memoria Juan Radrigán ha desarrollado durante sus veinticinco años de escritura teatral, desde Testimonio delas muertes de Sabina y L as brutas al final de la década del setenta e inicio de la del ochenta, hasta Beckett y Godot, Carta abierta y El desaparecido, todas del año 2004, ha situado siempre su teatro, en tanto producción cultural, entrelas fuerzas residuales y las emergentes, en oposición a las dominantes, en el panorama de la hegemonía en el C hile finisecular. $Y$ desde esta perspectiva el autor efectivamente señala un camino de resistencia y/o rebeldía frente al poder (C astro, 2005). Y a la vez, más allá de ese gesto política y culturalmente concreto y reconocible, resulta fuertemente sintomático en las cerca de treinta obras de teatro escritas y estrenadas hasta ahora por Juan Radrigán, así como en el inmenso y heterogéneo universo de puestas en escena al que sus textos han dado vida, la invariable aunque a veces sutil insistencia en que "algo" ha ocurrido, en que al gún agravio o crimen siempre ha sido cometido en contra de al gún ser humano - aunquela acción misma en cada caso/ficción pueda ser demuy diversa naturaleza- , cuyos antecedentes pueden y deben eventual mente ser rastreados y reconstruidos a través de un muchas veces crudo y duro proceso de aclaración de evidencias (Contreras, 2004), si no con el fin de castigar al responsable o culpable, por lo menos como exigencia moral, como último al egato y testimonio de dignidad humana. $Y$ es entonces cuando la potencia de la escritura, la belleza de la palabra y la profundidad de la reflexión de Juan Radrigán adquieren universalidad al hacerse cargo, entre otras dimensiones de lo humano, del amor y del dolor, dela herencia, dela vida y dela muerte, mirando a esta última siempre de frente (Pérez, 2004; Pérez cit. por Guerrero, 2003), desde la fragilidad propia de una forma de habitar el mundo a medio camino entre una relativa esperanza y la completa desesperanza. En palabras del autor:

Como habitante de este mundo, en todo momento me ha parecido de suma importancia humana saber por qué lloran los muertos y es eso lo que me ha Ilevado a escudriñar en los vivos; posiblemente sea esa filuda inquietud la que 
haya hecho dolorosa mi dramaturgia, pero no veo culpa en ello, sé que los hombres no somos culpables de la tristeza porque ella es más antigua que nosotros y estaba esperándonos cuando nacimos (2004a: 19).

\section{BIBLIO GRAFIA}

Albornoz, Adolfo. 2004. "Prólogo. Juan Radrigán, veinticinco afanosos años entre textos y escenas", en Juan Radrigán, Crónicas del amor furioso. Santiago, Chile: Ediciones Frontera Sur, pp. 7-15.

Bravo Elizondo, Pedro. 2000. "Juan Radrigán, la dictadura y su teatro", en H eidrun Adler y George Woodyard, (eds.), Resistencia y poder: Teatro en Chile. Madrid: Vervuert-Iberoamericana, pp. 99-111.

Cánovas, Rodrigo. 1986. "Ictus y Radrigán: M ejorando al hombre", Lihn, Zurita, Ictus, Radrigán: Literatura chilena y experiencia autoritaria. Santiago, Chile: Flacso.

Castro, Alfredo. 2005. "Radrigán y G riffero", texto leído en abril de 2005, en el Teatro M ori, Santiago, en la presentación de las antologías Crónicas del amor furioso deJuan Radrigán y D iez obras defin desi glo de Ramón Griffero, ambas publicadas por Ediciones Frontera Sur, disponible en www.griffero.cl

Contreras, M arta. 2004. "Escenas casi familiares en Fantasmas borrachos de Juan Radrigán en la puesta en escena de Francisco Albornoz. 0 un estudio del amor y la soledad con un poco de humor", ponencia presentada en abril de 2003, con el título "Escenas casi familiares: Juan Radrigán/Francisco Albornoz", en la U niversidad de Concepción, en el Seminario "Teatro chileno y sus al rededores: Fantasmas borrachosdeJuan Radrigán, Perspectivas multidisciplinarias", y publicada bajo su título definitivo en Acta Literaria N ${ }^{\circ} 29$, pp. 149-154.

Guerrero, Eduardo. 2001. "Entrevista con Juan Radrigán”, Acto único: D ramaturgos en escena. Santiago, Chile: Ril Editores-U niversidad Finis Terrae, pp.137-155

Guerrero, Eduardo. 2003. "Entrevista con Rodrigo Pérez", Acto úni co: D irectores en escena, Santiago, C hile: Ril Editores-U niversidad Finis Terrae, pp.131-142.

H urtado, M aría de la Luz y Piña, Juan Andrés. 1984. "Los niveles demarginalidad en Radrigán", en Juan Radrigán, Teatro de Juan Radrigán: 11 obras, Santiago, C hile: Ceneca-U niversidad de M innesota, pp. 7-31.

Pérez, Rodrigo. 2004. "Presentación. Estupefacto, disconforme y proclive a la angustia: Juan Radrigán", en Juan Radrigán, Crónicas del amor furioso. Santiago, Chile: Ediciones Frontera Sur, pp. 5-6.

Radrigán, Juan. 1982. H echos consumados: Tres obras Santiago, C hile: M inga.

--- . 1984. Teatro de Juan Radrigán: 11 obras. Santiago, Chile: Ceneca-U niversidad de M innesota.

- - - . 1994. "Testimonio", en Elba Andrade y Walter Fuentes, Teatro y dictadura en Chile: antología crítica. Santiago, C hile: Ediciones D ocumentas.

--- . 2004a. "M emorias del olvido", conferencia lé da en octubre de 2002, con el título de "Pasante de memoria", en el Festival de Teatro de Bayonne, Francia, y 
publicada bajo su título definitivo en Crónicas del amor furioso. Santiago, Chile: Ediciones Frontera Sur.

--- . 2004b. Crónicas del amor furioso. Santiago, Chile: Ediciones Frontera Sur.

Vidal, H ernán. 1984. "Juan Radrigán: Los límites de la imaginación dialógica”, en Juan Radrigán, Teatro de Juan Radrigán: 11 obras. Santiago, Chile: Ceneca-U niversidad de M innesota, pp. 33-49.

Zegers, M aría Teresa. 1999. "Juan Radrigán: Un alegato por la dignidad delos marginados", 25 años de teatro en Chile. Santiago, Chile: M inisterio de Educación. 